\title{
Interactions among Escovopsis, Antagonistic Microfungi Associated with the Fungus-Growing Ant Symbiosis
}

\author{
Yuliana Christopher ${ }^{1,2}$, Celestino Aguilar $\left.{ }^{1,3}{ }^{(}\right)$, Dumas Gálvez ${ }^{4,5,6}{ }^{(}$, William T. Wcislo ${ }^{5}$, Nicole M. Gerardo ${ }^{7}$ and \\ Hermógenes Fernández-Marín 1,6,* \\ 1 Centro de Biodiversidad y Descubrimiento de Drogas, Instituto de Investigaciones Científicas y Servicios de \\ Alta Tecnología (INDICASAT AIP), Panamá 0843-01103, Panama; yulianachristopher83@gmail.com (Y.C.); \\ aguilar2587c@gmail.com (C.A.) \\ 2 Department of Biotechnology, Acharya Nagarjuna University, Guntur 522510, Andhra Pradesh, India \\ 3 Departamento de Microbiología Médica, Universidad de Panamá, Panamá 0824, Panama \\ 4 Programa Centroamericano de Entomología, Universidad de Panamá, Panamá 0824, Panama; \\ galvezd@gmail.com \\ 5 Smithsonian Tropical Research Institute, Balboa, Ancón, Panamá P.O. Box 0843-03092, Panama; \\ wcislow@si.edu \\ 6 Sistema Nacional de Investigación, Panamá 0816-02852, Panama \\ 7 Department of Biology, Emory University, Atlanta, GA 30322, USA; ngerard@emory.edu \\ * Correspondence: hfernandez@indicasat.org.pa
}

Citation: Christopher, Y.; Aguilar, C.; Gálvez, D.; Wcislo, W.T.; Gerardo, N.M.; Fernández-Marín, H. Interactions among Escovopsis, Antagonistic Microfungi Associated with the Fungus-Growing Ant Symbiosis. J. Fungi 2021, 7, 1007. https://doi.org/10.3390/jof7121007

Academic Editor: Ivan M. Dubovskiy

Received: 3 September 2021

Accepted: 13 November 2021

Published: 25 November 2021

Publisher's Note: MDPI stays neutral with regard to jurisdictional claims in published maps and institutional affiliations.

Copyright: (c) 2021 by the authors. Licensee MDPI, Basel, Switzerland. This article is an open access article distributed under the terms and conditions of the Creative Commons Attribution (CC BY) license (https:/ / creativecommons.org/licenses/by/ $4.0 /)$.

\begin{abstract}
Fungi in the genus Escovopsis (Ascomycota: Hypocreales) are prevalent associates of the complex symbiosis between fungus-growing ants (Tribe Attini), the ants' cultivated basidiomycete fungi and a consortium of both beneficial and harmful microbes found within the ants' garden communities. Some Escovopsis spp. have been shown to attack the ants' cultivated fungi, and coinfections by multiple Escovopsis spp. are common in gardens in nature. Yet, little is known about how Escovopsis strains impact each other. Since microbe-microbe interactions play a central role in microbial ecology and evolution, we conducted experiments to assay the types of interactions that govern Escovopsis-Escovopsis relationships. We isolated Escovopsis strains from the gardens of 10 attine ant genera representing basal (lower) and derived groups in the attine ant phylogeny. We conducted in vitro experiments to determine the outcome of both intraclonal and interclonal Escovopsis confrontations. When paired with self (intraclonal interactions), Escovopsis isolated from lower attine colonies exhibited antagonistic (inhibitory) responses, while strains isolated from derived attine colonies exhibited neutral or mutualistic interactions, leading to a clear phylogenetic pattern of interaction outcome. Interclonal interactions were more varied, exhibiting less phylogenetic signal. These results can serve as the basis for future studies on the costs and benefits of Escovopsis coinfection, and on the genetic and chemical mechanisms that regulate the compatibility and incompatibility observed here.
\end{abstract}

Keywords: vegetative incompatibility; intermingling; antagonism; fungus-growing ants; coinfection; Attini; Escovopsis

\section{Introduction}

Escovopsis (Ascomycota: Hypocreales) is a diverse genus of microfungi that has only ever been found in association with gardens of fungus-growing ants (Tribe Attini). Escovopsis spp. are best known as mycoparasites of the basidiomycete fungi that the ants cultivate for food [1-3], though the virulence of species varies and the ecological roles of many Escovopsis spp. have not been characterized [1]. Co-cladogenesis analyses suggest a pattern indicative of co-diversification of the mutualistic hosts (ants and their cultivated fungi) and Escovopsis [4-9] at broad taxonomic scales, with less fidelity at finer scales of resolution [10-12]. Additionally, a fourth symbiotic taxon, actinomycete bacteria, inhabit the ants' cuticles and produce antifungal compounds that inhibit the growth of 
some Escovopsis spp. [8,13-16]. Studies of interactions among members of the system highlight that there can be both competition [17] and coexistence between ant species [18], somatic incompatibility between cultivar strains [19] and antagonistic interactions between actinomycete bacteria [20,21]. Less, however, is known about interactions among Escovopsis species or strains. The few studies that have been carried out have been restricted to studies on Escovopsis associated to leaf-cutter ants. Their findings indicated little antagonism between the Escovopsis spp., which could facilitate coinfection [12,22] and coexistence, however this may not be representative of Escovopsis's diversity. Escovopsis coinfections in attine ant gardens have been reported to be found in the colonies of many fungusgrowing ant species [12,22-24]. Coinfections of a single host by multiple parasites are common in many natural host-parasite systems [25]. Parasite coinfection may facilitate parasites' abilities to establish, replicate and persist within hosts [26,27]. Alternatively, parasites and pathogens may inhibit one another's establishment and replication, lessening virulence [28-34]. Co-infections may also influence transmission processes [35,36], and more broadly the structure and evolution of microbial communities [37,38]. To begin to elucidate how Escovopsis microfungi interact with one another, we extensively collected and sequenced Escovopsis isolated from colonies of 10 genera of attine ants found in Panama. We randomly selected one strain of Escovopsis isolated from gardens of 12 species of ants for use in in vitro confrontations and used a phylogenetic approach to analyze the distribution of interaction outcomes.

\section{Materials and Methods}

\subsection{Nest Collection and Escovopsis Isolation}

We collected colonies from 2013 to 2016 at multiple localities in the Republic of Panama (Table S1). Small attine ant colonies were maintained in sterile Petri dishes $(100 \times 15 \mathrm{~mm})$, while larger colonies were placed in plastic containers, previously sterilized with $70 \%$ ethanol. We fed colonies corn meal or fresh leaves and placed a piece of paper soaked with sterile water in each container. To isolate Escovopsis strains, we followed methods described in [24].

\subsection{DNA Extraction, Sequencing and Phylogenetic Analyses}

DNA from 240 Escovopsis-like strains was extracted from mycelia of pure cultures following [39]. We amplified PCR products of two different nuclear DNA markers: the Internal Transcribed Spacer (ITS) and the Large Subunit rRNA (LSU). The primers and conditions used for amplification are described in Table 1. PCR products were cleaned with the QIAquick PCR Purification kit (Qiagen, Hamburg, Germany) following the supplier's instructions and sequenced by Eurofins Genomics (Germany). DNA sequences were checked and assembled using Geneious Prime 2019 (https: / / www.geneious.com, accessed on 15 August 2021). All newly generated sequences were deposited to the National Center for Biotechnology Information (NCBI) Taxonomy Database (https: / / www.ncbi.nlm.nih. gov, accessed on 10 August 2021) GenBank with accession numbers MZ959192-MZ959282 and MZ964338-MZ964401 for LSU and ITS sequences, respectively (Table S1).

Table 1. Primers used for PCR and sequencing of Escovopsis strains.

\begin{tabular}{|c|c|c|}
\hline Marker & Primers & PCR and Sequencing Conditions \\
\hline ITS & $\begin{array}{c}\text { ITS4- 5'TCCTCCGCTTATTTGATTATTGATC3' } \\
\text { ITS5- 5'GGATATGTATATATATGTCGTATATCATATGG3' [40] }\end{array}$ & $\begin{array}{c}3 \text { min of denaturation at } 96^{\circ} \mathrm{C}, 35 \text { cycles } \\
\text { consisting of } 1 \text { min at } 94^{\circ} \mathrm{C}, 1 \mathrm{~min} \text { at } 55^{\circ} \mathrm{C} \text { and } \\
2 \min \text { at } 72^{\circ} \mathrm{C}[41]\end{array}$ \\
\hline LSU & $\begin{array}{l}\text { CLAF-5'GCATTATTCATATTATATGCGGATGGAT 3' } \\
\text { CLAR-5'GATCTCCTTGGTCCGTGTTTCAT 3' [7] }\end{array}$ & $\begin{array}{c}2 \mathrm{~min} \text { of denaturation at } 95^{\circ} \mathrm{C}, 40 \text { cycles of } 30 \mathrm{~s} \\
\text { at } 95^{\circ} \mathrm{C}, 1 \mathrm{~min} \text { at } 62^{\circ} \mathrm{C}, 90 \mathrm{~s} \text { at } 72{ }^{\circ} \mathrm{C} \text { and } 5 \mathrm{~min} \\
\text { of extension at } 72{ }^{\circ} \mathrm{C}[39]\end{array}$ \\
\hline
\end{tabular}

For phylogenetic analyses, we included all strains that were successfully sequenced as well as representative sequences from ten named Escovopsis species [39,41-43] and one species from the genus Escovopsioides [39] obtained from GenBank, as shown in Table S1. We used Hypocrea lutea and Hypomyces spp. as outgroups. The final dataset comprised two files, one for LSU with 109 taxa and the other for ITS with 78 taxa. 
We performed separate phylogenetic reconstructions for LSU and ITS. Alignments were performed with MAFFT 1.4.0 [44] as implemented in Geneious Prime 2019 (https: / / www.geneious.com, accessed on 15 August 2021) with default parameters. The appropriate nucleotide substitution model for each gene was determined by using JModelTest2 on XSEDE 2.1.6 [45]. Using AIC, GTR + I + G was estimated as the best-fit model for LSU, and GTR + G was estimated as the best-fit model for the full ITS dataset.

Maximum-likelihood (ML) and Bayesian Inference (BI) analyses were implemented on the CIPRES Science Gateway portal (https: / / www.phylo.org, accessed on 22 August 2021) using RAxML-HPC2 on XSEDE 8.2.12 and MrBayes on XSEDE 3.2.7) [46,47], respectively. For ML analyses, the default parameters were used. BI was carried out using the rapid bootstrapping algorithm with the automatic halt option. Bayesian analyses included five parallel runs of 5,000,000 generations, with the stop rule option and a sampling frequency of 1000 generations. The burn-in fraction was set to 0.25 , and posterior probabilities (PP) were determined from the remaining trees. The resulting trees were plotted using FigTree v.1.4.2 and edited with Graphic 3.1.

\subsection{Evaluation of Escovopsis-Escovopsis Interaction Outcomes}

\subsubsection{Intraclonal Confrontation Bioassays}

To conduct confrontation in vitro bioassays of intraclonal pairwise combinations, we chose a single Escovopsis strain isolated from each one of 12 attine ant species from genera representing lower and derived groups across the attine phylogeny [48,49]. These included the more basal "lower" attine species Cyphomyrmex muelleri, C. longiscapus, $C$. sp., Apterostigma auriculatum, Ap. collare and Ap. dentigerum, and the more derived "higher" attine species Atta sexdens, At. cephalotes, At. colombica, Mycetomoellerius zeteki, Paratrachymyrmex cornetzi and Trachymyrmex sp.10. For each confrontation bioassay, we cut $6.5 \mathrm{~mm}$ agar discs from pure Escovopsis strain cultures on Potato Dextrose Agar (PDA). These discs contained approximately $5.0 \times 10^{6}$ conidia. The discs were placed on opposite sides of a $100 \mathrm{~mm}$ Petri dish. As controls, each of the 12 Escovopsis cultures was also paired with a mycelium-free PDA agar block (Figure S1). Each intraclonal interaction and their controls were replicated three times. Petri dishes were maintained in a plastic container at room temperature under a 10:14 hr light:dark cycle. Dishes were photographed after 20 days. We measured the area of growth of all isolates using Image [50]. From photographs, we categorized the outcome of each interaction based on previous studies for fungi [51,52], which are explained further below.

\subsubsection{Interclonal Confrontation Bioassays}

To assess the outcome of interclonal interactions, we used 8 of the 12 Escovopsis strains from the previous experiment. These strains were isolated from gardens of Apterostigma pilosum, Ap. collare, Cyphomyrmex sp., C. longiscapus, Trachymyrmex sp10, Paratrachymyrmex cornetzi, Atta colombica, and At. cephalotes. We used the same protocol as described above. As controls, each of the Escovopsis strains were also paired with themselves in intraclonal bioassays and with mycelium-free PDA agar blocks.

\subsubsection{Bioassay Outcome Quantification}

We categorized the outcome of the interactions as described by [51,52]. The interactions were assigned to one of four outcomes: (1) commensal intermingling (both fungi grow into one another without making an inhibition zone); (2) overgrowth (one isolate grows over the other); (3) invasion/replacement (mycelium of one of the isolates grows into the other and finally replaces it); (4) inhibition, including inhibition at the contact zone (fungi approached each other until almost in contact, with a narrow (1-2 $\mathrm{mm}$ ) demarcation zone) and inhibition at distance (inhibition at a distance of $>2 \mathrm{~mm}$ between fungi) (Figure 1). In addition, we adapted the protocols by [51,52] for analyses based on numerical scores, ranging from one to four, employing three different traits: antagonism index, resistance percentage, and inhibition percentage. 


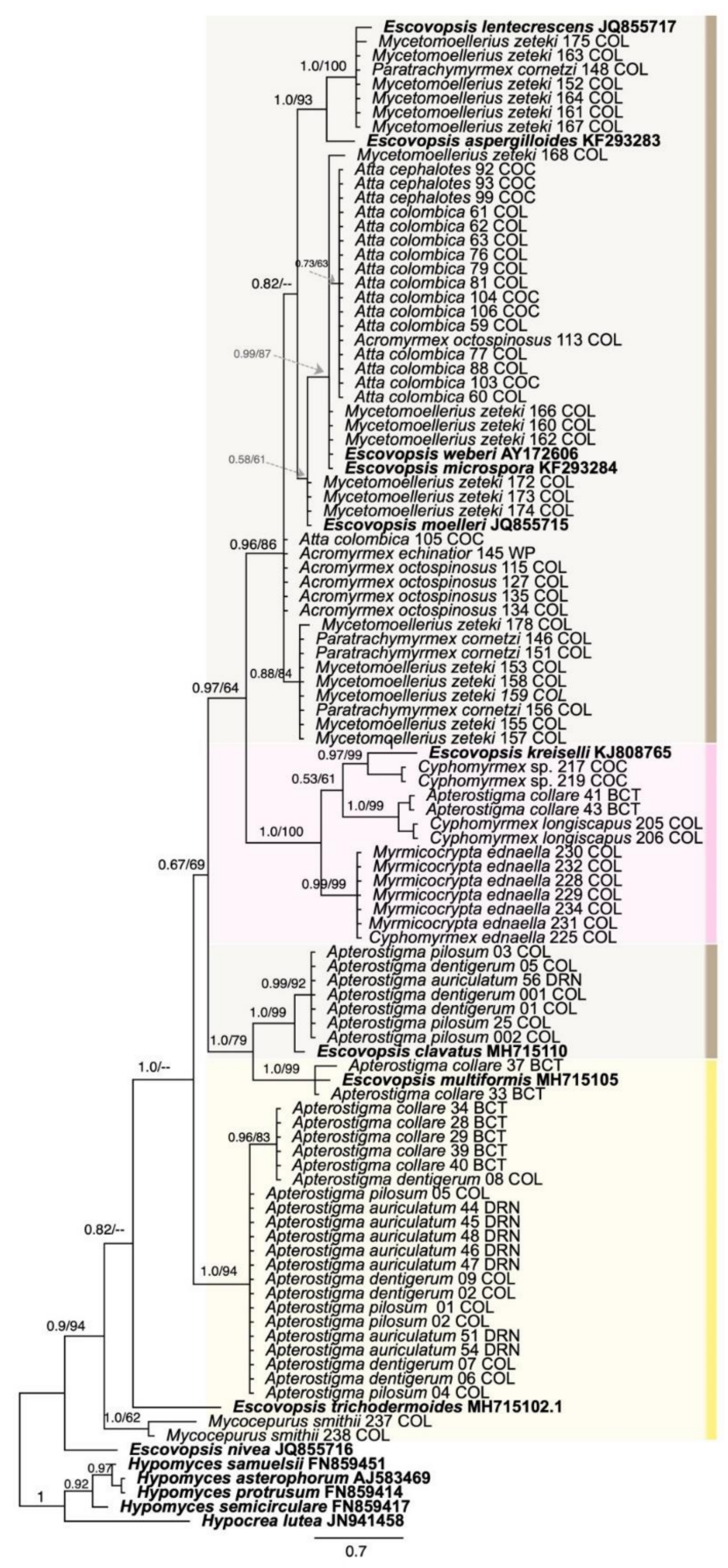

Figure 1. Phylogeny based on Large Subunit rRNA (LSU) of Escovopsis strains from fungus-growing ant gardens. The phylogenetic tree shown is based on the Bayesian tree topology. Each fungal strain isolated as part of this study is indicated by the species name of the ant host garden from which the Escovopsis was isolated, and all other strains are indicated by their genus and species name, followed by the Genbank accession number. Hypocrea lutea was used as an outgroup. Different colors indicate the Escovopsis morphotypes shown in the phylogenetic analyses. The numbers on branches indicate the posterior probabilities and the bootstrap support values, respectively. Only bootstrap supports $\geq 50 \%$ of ML and the posterior probability values $\geq 0.5$ of BI analyses are indicated above or below the respective branches. The provinces from which each strain was isolated are indicated by the following abbreviations: PA, Panamá; COC, Coclé; COL, Colón; DRN, Darién; BCT, Bocas del Toro; WP, West Panamá. Scale bar 0.7 substitutions per site. 
For occurrences of inhibition, we measured the area of the zone of inhibition. The percentage of inhibition (\% inhibition) was calculated as the area of an Escovopsis strain growing alone (control) divided by the growth area of the same strain in a confrontation bioassay against another Escovopsis strain $\times 100$. A value of zero was assigned for those that did not show any inhibition [52]. Moreover, we used the percentage of resistance, which represented the ability of a given species to grow and resist the presence of another fungus, and the antagonism index, which represented the ability of a species to dominate and to compete with other species [52]. To calculate the percentage of resistance and the antagonism index we used the equations by [52].

\subsection{Statistical Analyses}

Based on a phylogeny estimated from ITS sequences of the Escovopsis isolates, we analyzed intraclonal confrontation bioassays by using phylogenetically independent contrasts [53] (Garland et al., 1993), as implemented in R (R Development Core Team) [54]) with the function 'phylANOVA' (package 'phytools'), to test for Escovopsis clade differences in resistance, area of inhibition (inhibition zone) and antagonism index. We performed 1000 simulations for each test.

For the interclonal confrontation bioassays, to test whether outcomes (type of interaction) varied across combinations of isolates associated with lower attines, derived attines and between the two groups, we performed a multinomial regression as implemented in the function 'multinom' (package nnet) and performed Tukey posthoc tests (Tukey-adjusted $p$-values) as implemented in the function 'Imeans' (package lsmeans).

\section{Results}

\subsection{Diversity of Escovopsis Isolates}

We collected 220 colonies of 19 species of ten genera of fungus-growing ants: Atta colombica, At. cephalotes, At. sexdens, Acromyrmex echinatior, Ac. octospinosus, Trachymyrmex sp. 10, Mycetomoellerius zeteki, Paratrachymyrmex cornetzi, Sericomyrmex amabilis, Apterostigma collare, Ap. dentigerum, Ap. auriculatum, Ap. pilosum, Cyphomyrmex longiscapus, C. muelleri, C. costatus, C. sp., Mycocepurus smithii and Myrmicocrypta sp. From these colonies, we isolated pure cultures of 162 Escovopsis strains (47 from colonies of Atta spp., 16 from colonies of Acromyrmex spp., 45 from colonies of Apterostigma spp., 12 from colonies of Cyphomyrmex spp., 2 from colonies of Trachymyrmex sp. 10, 20 from colonies of Mycetomoellerius zeteki, 4 from colonies of Paratrachymyrmex cornetzi, 6 from colonies of Myrmicocrypta sp., 6 from colonies of Mycocepurus smithii and 4 from colonies of Sericomyrmex amabilis. (Table S1). Across these samples, we observed that spore color and morphology varied. Brown-spored strains of Escovopsis were most commonly isolated from fungus gardens of Apterostigma, Atta, Acromyrmex, Trachymyrmex, Paratrachymyrmex, Mycetomoellerius, and Sericomyrmex; pink-spored strains were most commonly isolated from fungus gardens of Cyphomyrmex, Apterostigma and Myrmicocrypta; and yellow-spored strains were isolated from Apterostigma and Mycocepurus gardens.

A total of 155 new sequences from Escovopsis spp. were deposited in the NCBI database and their accession numbers are provided in Table S1. The alignments of ITS and LSU had lengths of $563 \mathrm{bp}$ and $541 \mathrm{bp}$, respectively. For both gene markers, the topologies of the BI and ML trees are basically congruent with variable support values, therefore only one tree topology (with nodal support from both methods) is shown for each (Figures 1 and 2). The recently collected Escovopsis strains reported in this study were largely grouped according to the colors of the spores (brown, pink and yellow, including yellowish) in both phylogenies (Figures 1 and 2). The Escovopsis isolated from colonies of Atta, Acromyrmex, Trachymyrmex, Paratrachymyrmex, Mycetomoellerius and Sericomyrmex grouped together with the named species E. weberi, E. microspora, E. moelleri and E. aspergilloides, E. lentecrescens, E. primorosea, E. catenulata and E. longivesica (Figures 1 and 2). The brown-spored strains of Escovopsis isolated from colonies of Ap. auriculatum, Ap. dentigerum, Ap. collare, Ap. pilosum grouped together with E. clavatus and E. multiformis. The pink-spored strains of Escovopsis isolated from Ap. collare, Ap. auriculatum, Cyphomyrmex spp. and Myrm. ednaella colonies grouped with E. kreiselli, the only pink-spored species described for Escovopsis (Figures 1 and 2). Most yellow-spored Escovopsis strains (including yellowish white) collected from colonies of Ap. collare, Ap. auriculatum, Ap. 
dentigerum and Ap. pilosum formed a separate clade in the phylogenies (Figures 1 and 2), while the yellow-spored strains isolated from Mycocepurus smithii colonies grouped together with $E$. trichodermoides (Figure 2).

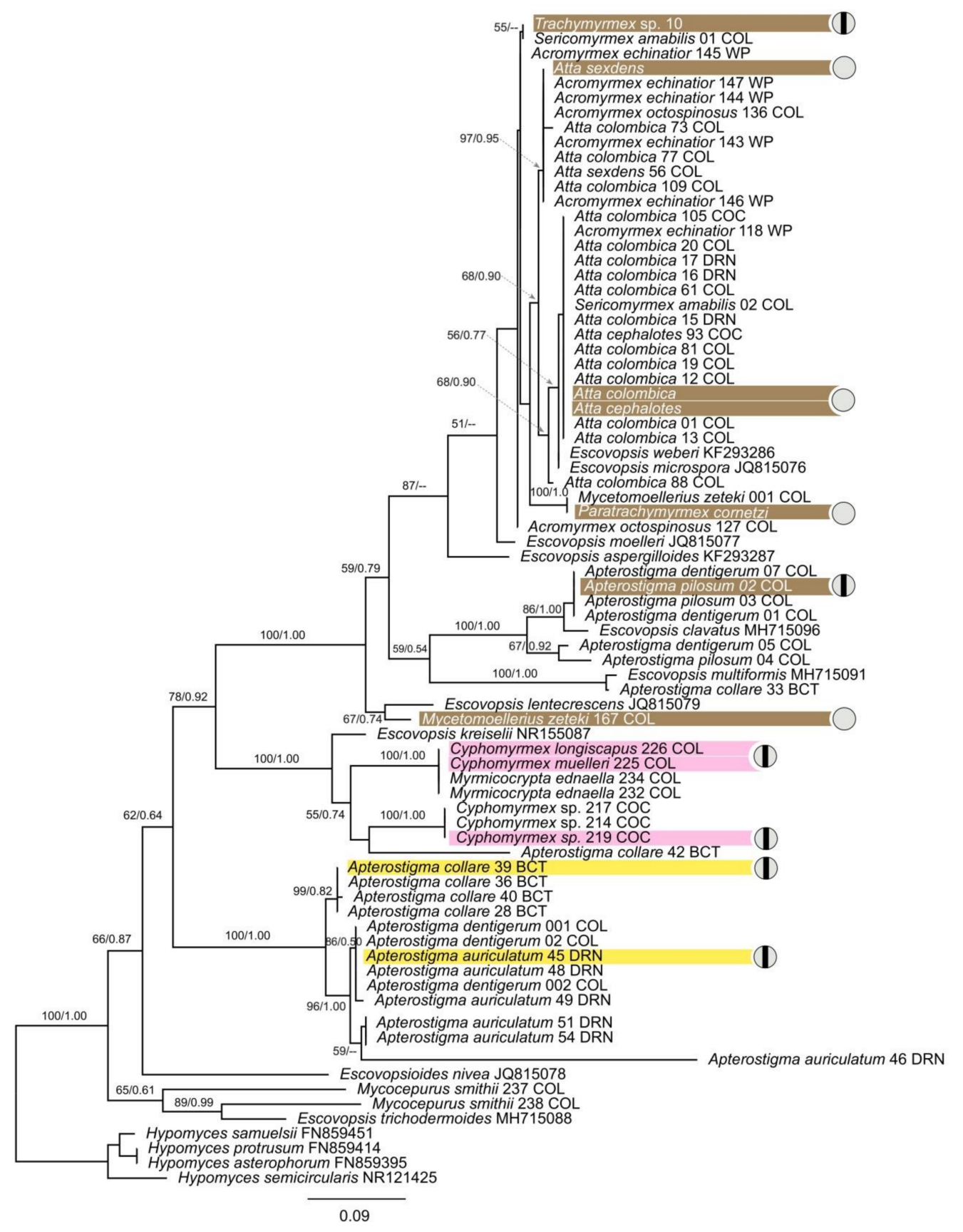

Figure 2. Phylogenetic tree based on ITS rDNA sequences of Escovopsis strains from fungus-growing ant gardens. The phylogenetic tree shown is based on the maximum likelihood tree topology. Escovopsis strains isolated from lower attine colonies (Apterostigma auriculatum, Ap. collare, Ap. pilosum, Cyphomyrmex longiscapus, C. muelleri and Cyphomyrmex sp.) and strains isolated from derived attine colonies (Trachymyrmex sp10, Mycetomoellerius zeteki, Paratrachymyrmex cornetzi, Atta colombica, At. cephalotes and $A$. sexdens). Each strain isolated as part of this study is indicated by the species name of the ant host garden from which the Escovopsis was isolated, and all other strains are indicated by their genus and species name, followed by the Genbank accession number. Hypomyces species were used as outgroups. Bootstrap supports ( $\geq 50 \%$ ) of ML and the posterior probability values $(\geq 0.5)$ of $\mathrm{BI}$ analyses are indicated above or below the respective branches. Branch color indicates fungal spore color. The provinces from which each strain was isolated are indicated by the abbreviations detailed in Figure 1. Closed grey circles show intermingling, a non-antagonistic form of interaction, while split grey circles mean inhibition, a form of antagonistic interaction. Scale bar represents 0.09 substitutions per site. 


\subsection{Intraclonal Confrontation Bioassays}

Intraclonal confrontation bioassays between Escovopsis strains exhibited distinct outcomes (Figures 2 and 3). The interactions fell into five general classes: intermingling, overgrowth, invasion/replacement, inhibition at touching and inhibition at a distance (Figures 3 and 4F). Outcomes were consistent across replicates.

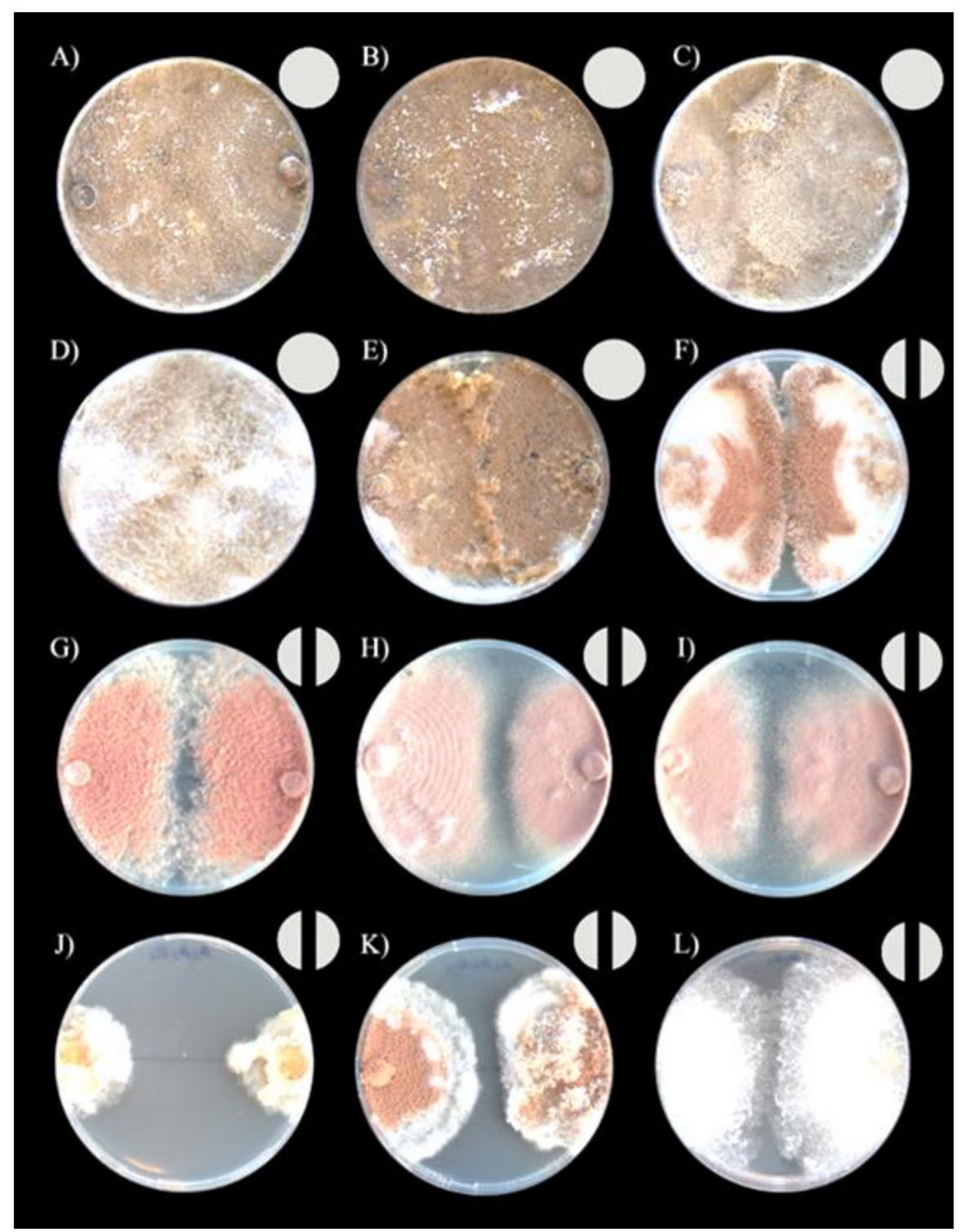

Figure 3. Intraclonal confrontation bioassays between Escovopsis strains. (A) Escovopsis sp. from At. colombica, intermingling; (B) Escovopsis sp. from At. cephalotes, intermingling and (C) At. sexdens, intermingling; (D) Escovopsis sp. from Par. cornetzi, intermingling; (E) Escovopsis sp. from Myc. zeteki, intermingling; (F) Escovopsis sp. from T. sp10, inhibition; (G) Escovopsis sp. from C. sp. colony, inhibition; (H) Escovopsis sp. from C. longiscapus colony, inhibition; (I) Escovopsis sp. from C. muelleri colony, inhibition; (J) Escovopsis sp. from Ap. auriculatum colony, inhibition; (K) Escovopsis from Ap. pilosum colony, inhibition and (L) Escovopsis sp. from Ap. collare colony, inhibition. Each photo shows in the top right the symbol of the interaction type that represents it. 

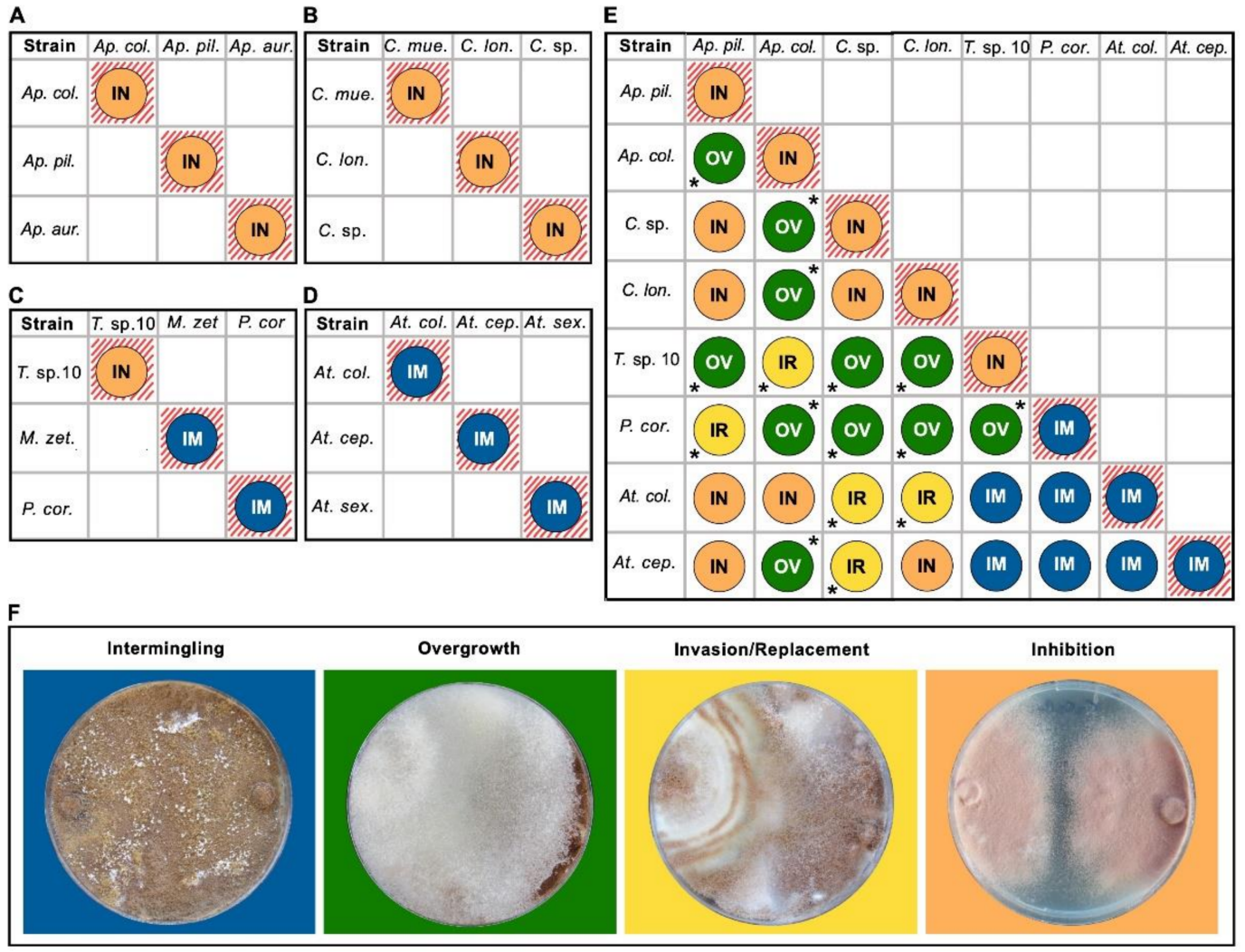

Figure 4. Outcomes of intra- and interclonal confrontation bioassays. The left, top quadrants (A-D) indicate outcomes of intraclonal interactions for 12 Escovopsis strains isolated from colonies of the lower attine ant genera, Apterostigma (A) and Cyphomyrmex (B), and derived genera, including Trachymyrmex, Mycetomoellerius, and Paratrachymyrmex (C), and Atta (D). The right, top quadrant (E), indicates results of factorial interactions among eight Escovopsis isolated from colonies of eight attine ant species. Boxes with lines are intraclonal interactions, and those without lines are interclonal interactions. The asterisk positioned on the bottom left of the interaction type symbol indicates that the strain that grows in excess or replaces it is the one indicated in the row, while an asterisk positioned on the top right of the interaction type indicates that the strain that grows in excess or replaces it is the one indicated in the column. (F) Representative interaction outcomes. Intermingling occurs when both fungi grow into one another without any inhibition zone. Overgrowth occurs when one strain grows towards and completely covers the other. Invasion/replacement occurs when one strain grows towards the other and then begins to consume it, or in some cases, completely replaces it. Inhibition occurs when strains approach each other but leave a demarcation line between them. Abbreviations and full names: Ap. col, Apterostigma collare; Ap. pil, Ap. pilosum; Ap. aur, Ap. auriculatum; C. sp, Cyphomyrmex sp.; C. mue, C. muelleri; C. lon, C. longiscapus; At. col, Atta colombica; At. cep, At. cephalotes; At. sex, At. sexdens; T. sp 10, Trachymyrmex sp. 10; Myc. zet, Mycetomoellerius zeteki; Par. cor, Paratrachymyrmex cornetzi.

Escovopsis strains isolated from Apterostigma colonies exhibited intraclonal inhibition indicative of vegetative incompatibility (Figure 4). Specifically, we found inhibition at contact for the strain isolated from an A. collare colony, while the strains isolated from A. pilosum and A. auriculatum colonies exhibited inhibition at distance. Escovopsis isolated from Cyphomyrmex colonies also exhibited inhibition: the strain isolated from a Cyphomyrmex sp. colony exhibited inhibition at the contact point, while the strains isolated from C. muelleri and C. longiscapus colonies presented inhibition at a distance. Escovopsis strains isolated from colonies of the more derived attines most often exhibited intermingling, though Escovopsis from Trachymyrmex sp10 exhibited inhibition at contact (Figure 4). Overall, Escovopsis strains associated with lower attine ants (Apterostigma, Cyphomyrmex) tended to be more self-antagonistic than those from gardens of the more derived ant genera (Trachymyrmex, Mycetomoellerius, Paratrachymyrmex, Atta), as measured by resistance percentage (1105.0 \pm 56.4 vs. $173.3 \pm 424.4$, respectively; phylogenetic independent contrasts: $\mathrm{F}=28.4, p=0.001$ ), inhibition percentage ( $33 \pm 16$ vs. $2.9 \pm 7$, respectively; phylogenetic 
independent contrasts: $\mathrm{F}=16.2, p=0.005)$ and antagonism index (10.5 \pm 1.6 vs. $4.0 \pm 2.4$, respectively; phylogenetic independent contrasts: $\mathrm{F}=29.1, p=0.003$ ).

\subsection{Interclonal Confrontation Bioassays}

Overall, there were differences in the outcomes of intraclonal interactions depending on the ant group (lower vs. derived) to which the strains were associated (LR test, $\mathrm{X}^{2}=168.6, p<0.001$, Figures 3 and 4 ). Inhibition was significantly more common for the strain combination lower-lower as compared to the combinations of derived-lower $(\mathrm{t}$ ratio $=6.67, p<0.001)$ and derived-derived $(\mathrm{t}$ ratio $=9.6$, d.f. $=9, p<0.0001)$. Overgrowth of one strain over the other one was significantly more common in the combination of derived-lower as compared to the derived-derived combination ( $\mathrm{t}$ ratio $=4.3$, d.f. $=9, p=0.005$ ) and tended to be higher than the lower-lower combination, although this difference was not statistically significant $(\mathrm{t}$ ratio $=-2.6$, d.f. $=9, p=0.07)$. Invasion/replacement was higher for the derived-lower combination as compared to the lowerlower ( $\mathrm{t}$ ratio $=-4.7$, d.f. $=9, p=0.003$ ) and the derived-derived combinations ( $\mathrm{t}$ ratio $=4.7$, d.f. $=9, p=0.003$ ). Finally, intermingling only occurred in the derived-derived combination, making it statistically significantly more common in the derived-derived as compared to the lower-lower $(\mathrm{t}$ ratio $=-14.4$, d.f. $=9, p<0.0001)$ and derived-lower combinations ( $\mathrm{t}$ ratio $=-14.4$, d.f. $=9, p<0.0001)$.

\section{Discussion}

We highlight the phenotypic and genetic diversity of Escovopsis at a local scale and begin to assess the potential for antagonistic and mutualistic interactions amongst Escovopsis strains. Our results indicate that some of the described species of Escovopsis, which have most often been described based on isolates from South America, occur in Panama. Based on sequences of ITS and LSU, some of the 160 Escovopsis strains appear to be representatives of eight named species: E. weberi (the only previously named species reported from Panama [55]), E. microspora, E. moelleri, E. lentecrescens, E. clavatus, E. kreiselli, E. multiformis and E. trichodermoides. The brown-spored Escovopsis strains isolated from Ap. auriculatum, Ap. dentigerum, Ap. collare, and Ap. pilosum grouped together with E. clavatus and E. multiformis, consistent with the results of Montoya et al., [43], who isolated these species from colonies of Apterostigma spp. in Brazil. The yellow-spored strains of Escovopsis isolated from colonies of Mycocepurus smithii grouped with E. trichodermoides, associates of Mycocepurus goeldii and Mycetophylax morschi in Brazil [42,56]. However, the Escovopsis strains isolated from Acromyrmex spp. in Panama did not group with Escovopsis species isolated from Acromyrmex spp. in Argentina [57]. Several clades of Panamanian Escovopsis had no match to described species (Figures 1 and 2), highlighting the need for future taxonomic work on Escovopsis. We likely did not capture the full diversity of Escovopsis in the Panamanian isthmus, and more sampling of colonies of widely distributed ant species, such as Mycocepurus smithii (see Kellner et al., 2018) [58] and Sericomyrmex amabilis, and from genera not included in this study, such as Myrmicocrypta, is needed. Filling in those gaps will provide better insight into the biogeographic distribution of Escovopsis species.

As for most organisms, recognition of self, of potential mates and of potential antagonists is crucial for fungi [59]. For ascomycetes, vegetative incompatibility (somatic recognition) frequently occurs when two fungal isolates of the same species come into contact [60]. If strains are from different incompatibility groups, they often reject each other, thus limiting genetic exchange, while if they are compatible, they may fuse. Furthermore, ascomycetes may exhibit recognition between species, including pathogen recognition [60]. Below, rather than speculate as to the genetic, physiological and chemical basis of the compatibility and incompatibility observed, which indeed warrant future investigation, we discuss our results within an ecological and evolutionary framework.

Intraclonal interactions of Escovopsis strains led to two outcomes, inhibition and intermingling. Intraclonal inhibition was exhibited by Escovopsis strains associated with the lower attines (Apterostigma spp., Cyphomyrmex spp.) and the derived attine Trachymyrmex 
sp. 10, while non-antagonistic intermingling was exhibited by Escovopsis strains associated with the derived attines Mycetomoellerius zeteki, Paratrachymyrmex cornetzi and Atta spp. (Figures 2, 3 and 4A-D). Some ancestral characteristics seem to be retained in derived taxa, such as the Escovopsis strain isolated from Trachymyrmex sp. 10 that exhibited inhibitory interactions between clonal isolates (Figure 2, top of phylogeny). It is possible that interactions are regulated by genetic factors (i.e., compatibility/incompatibility loci) and mediated by the production of secondary compounds with antifungal properties. Escovopsis spp. produce an array of secondary metabolites [24,55,61,62], some of which have fungistatic and antifungal properties $[61,62]$

The ecological relevance of variation in self-compatibility is somewhat unclear. One hypothesis is that recognizing and inhibiting growth of self may be important in smaller colonies, such as those of the lower attines [63], where competing with oneself through vegetative overgrowth or intermingling could be more likely, and thus selected against. Alternatively, vegetative incompatibility may be selected for to prevent the spread of parasites (e.g., viruses), as has been seen in other systems [64,65]. Finally, vegetative incompatibility may be a byproduct of selection for inhibiting non-self competitors. Coinfections of colonies are common $[22,24,66]$ and, due to increased resource competition, coinfection of the smaller, lower attine colonies may place stronger selection on Escovopsis associated with these colonies to maintain mechanisms to inhibit the growth of other strains of the same species or other species.

Interclonal, interspecific interactions have been investigated in other systems in the context of how interactions may shape community assembly $[52,67]$. Results of interclonal interactions between Escovopsis ranged from no antagonism (i.e., intermingling) to varying degrees of antagonism (i.e., overgrowth, invasion/replacement, inhibition). Some form of antagonism was observed in $82 \%$ of interclonal assays, suggesting that interference competition between Escovopsis spp. may be a common consequence of coinfections. Despite this, coinfections are common in nature, which suggests either that the processes shaping Escovopis-Escovopsis interactions differ in more natural settings or that spatial segregation within gardens allows for co-existence. Future research should explore the dynamics of coinfection in the context of a larger array of Escovopsis pairings, employing tractable assays, such as those used here, and infections of ant gardens.

Interference between Escovopsis is interesting in light of research highlighting that that Escovopsis spp. exhibit host specificity $[11,68]$. For example, the pink-spored Escovopsis, like E. kresilli, are found in colonies of lower but not derived attines. Escovopsis' host ranges are shaped by both cultivar defenses [69] and actinomycete bacteria defenses [70,71], as strains of both microbes vary in terms of what Escovopsis spp. they inhibit. Interactions with the ants, other microbes and commensals in the gardens, along with additional biotic and abiotic factors, may also shape Escovopsis spp. specificity [11]. Our results indicate that interactions with other Escovopsis, some of which inhibit each other, should also be taken into consideration.

\section{Conclusions}

To summarize, an extensive collection of Escovopsis associated with the breadth of fungus-growing ant species found in Panama reveals unexplored diversity of this genus. While some Escovopsis spp. exhibit vegetative incompatibility, others do not. Furthermore, interspecific interactions differ markedly in their outcomes, with many exhibiting signs of antagonism, while others suggest that some Escovopsis-Escovopsis interactions may be neutral or mutualistic. These interactions should be further explored in terms of both the underlying proximate genetic and chemical mechanisms and how they shape ecological dynamics and evolution in the fungus-growing ant symbiosis.

Supplementary Materials: The following are available online at https: / www.mdpi.com/article/ 10.3390/jof7121007/s1, Table S1: Metadata for strains included in phylogenetic analyses and interactions experiments, colonies and sequence information used in this study. Figure S1: Intraclonal confrontation bioassays Escovopsis strains controls. 
Author Contributions: Conceived and designed the experiments: Y.C. and H.F.-M. Sampling: Y.C. and H.F.-M. Conducted the main experiments: Y.C., H.F.-M. and N.M.G. Analyzed the data: Y.C., H.F.-M., C.A., D.G. and N.M.G. Wrote the original draft: Y.C., H.F.-M., N.M.G. and W.T.W. Reviewed, edited and prepared the MS for submission: Y.C., H.F.-M., N.M.G., W.T.W., C.A. and D.G. All authors have read and agreed to the published version of the manuscript.

Funding: This work was supported by a doctoral fellowship from SENACYT grant to Y.C.; SNI grant 11-2020, FID 18-079 SENACYT grant, and research funds from INDICASAT-AIP to H.F.-M. general research funds from STRI to W.T.W., and NSF DEB-1754595 to N.M.G.

Institutional Review Board Statement: Not applicable.

Informed Consent Statement: Not applicable.

Data Availability Statement: All sequences generated in this study were submitted to GenBank.

Acknowledgments: We are grateful to Alejandro De Sedas-Maltéz, Genesis Chong, Manuel Valdéz and Paola Galgani for assistance with field work, and Tarik Acevedo-Gonzalez and Erica Harris for helping in the Gerardo laboratory. We thank the Ministerio de Ambiente for collecting permits, Instituto de Investigación Científicas y Servicios de Alta Tecnología (INDICASAT AIP) and the Smithsonian Tropical Research Institute (STRI).

Conflicts of Interest: The authors declare no conflict of interest.

\section{References}

1. De Mendonça, D.M.F.; Caixeta, M.C.S.; Martins, G.L.; Moreira, C.C.; Kloss, T.G.; Elliot, S.L. Low virulence of the fungi Escovopsis and Escovopsioides to a leaf-cutting ant-fungus symbiosis. Front. Microbiol. 2021, 12, 1-17. [CrossRef]

2. Varanda-Haifig, S.S.; Albarici, T.R.; Nunes, P.H.; Haifig, I.; Vieira, P.C.; Rodrigues, A. Nature of the interactions between hypocrealean fungi and the mutualistic fungus of leaf-cutter ants. Antonie Leeuwenhoek Int. J. Gen. Mol. Microbiol. 2017, 110, 593-605. [CrossRef]

3. Reynolds, H.T.; Currie, C.R. Pathogenicity of Escovopsis weberi: The parasite of the attine ant-microbe symbiosis directly consumes the ant-cultivated fungus. Mycologia 2004, 96, 955-959. [CrossRef] [PubMed]

4. Martin, M.M.; Gieselmann, M.J.; Martin, J.S. Rectal enzymes of attine ants: Alpha-amylase and chitinase. J. Insect. Physiol. 1973, 19, 1409-1416. [CrossRef]

5. Chapela, I.H.; Rehner, S.A.; Schultz, T.R.; Mueller, U.G. Evolutionary history of the symbiosis between fungus-growing ants and their fungi. Science 1994, 266, 1691-1694. [CrossRef]

6. Currie, C.R.; Mueller, U.G.; Malloch, D. The agricultural pathology of ant fungus gardens. Proc. Natl. Acad. Sci. USA 1999, 96, 7998-8002. [CrossRef] [PubMed]

7. Currie, C.R.; Wong, B.; Stuart, A.E.; Schultz, T.R.; Rehner, S.A.; Mueller, U.G.; Sung, G.H.; Spatafora, J.W.; Straus, N.A. Ancient tripartite coevolution in the attine ant-microbe symbiosis. Science 2003, 299, 386-388. [CrossRef]

8. Currie, C.R.; Poulsen, M.; Mendenhall, J.; Boomsma, J.J.; Billen, J. Coevolved crypts and exocrine glands support mutualistic bacteria in fungus-growing ants. Science 2006, 311, 81-83. [CrossRef]

9. Fernández-Marín, H.; Nash, D.R.; Higginbotham, S.; Estrada, C.; van Zweden, J.S.; d'Ettorre, P.; Wcislo, W.T.; Boomsma, J.J. Functional role of phenylacetic acid from metapleural gland secretions in controlling fungal pathogens in evolutionarily derived leaf-cutting ants. Proc. Biol. Sci. 2015, 282, 20150212. [CrossRef] [PubMed]

10. Gerardo, N.M.; Mueller, U.G.; Price, S.L.; Currie, C.R. Exploiting a mutualism: Parasite specialization on cultivars within the fungus-growing ant symbiosis. Proc. Royal Soc. B 2004, 271, 1791-1798. [CrossRef]

11. Birnbaum, S.S.; Gerardo, N.M. Patterns of specificity of the pathogen Escovopsis across the fungus-growing ant symbiosis. Am. Nat. 2016, 188, 52-65. [CrossRef]

12. Taerum, S.J.; Cafaro, M.J.; Little, A.E.; Schultz, T.R.; Currie, C.R. Low host-pathogen specificity in the leaf-cutting ant-microbe symbiosis. Proc. Biol. Sci. 2007, 274, 1971-1978. [CrossRef] [PubMed]

13. Currie, C.R.; Scott, J.A.; Summerbell, R.C.; Malloch, D. Fungus-growing ants use antibiotic-producing bacteria to control garden parasites. Nature 1999, 398, 701-704. [CrossRef]

14. Haeder, S.; Wirth, R.; Herz, H.; Spiteller, D. Candicidin-producing Streptomyces support leaf-cutting ants to protect their fungus garden against the pathogenic fungus Escovopsis. Proc. Natl. Acad. Sci. USA 2009, 106, 4742-4746. [CrossRef]

15. Oh, D.C.; Poulsen, M.; Currie, C.R.; Clardy, J. Dentigerumycin: A bacterial mediator of an ant-fungus symbiosis. Nat. Chem. Biol. 2009, 5, 391-393. [CrossRef]

16. Van Arnam, E.B.; Ruzzini, A.C.; Sit, C.S.; Horn, H.; Pinto-Tomás, A.A.; Currie, C.R.; Clardy, J. Selvamicin, an atypical antifungal polyene from two alternative genomic contexts. Proc. Natl. Acad. Sci. USA 2016, 113, 12940-12945. [CrossRef]

17. Jutsum, A.R.; Saunders, T.S.; Cherrett, J.M. Intraspecific aggression in the leaf-cutting ant Acromyrmex octospinosus. Anim. Behav. 1979, 27, 839-844. [CrossRef] 
18. Sanhudo, C.E.D.; Izzo, T.; Brandão, C.R.F. Parabiosis between basal fungus-growing ants (Formicidae, Attini). Insect. Soc. 2008, 55, 296-300. [CrossRef]

19. Poulsen, M.; Boomsma, J.J. Mutualistic fungi control crop diversity in fungus-growing ants. Science 2005, 307, 741-744. [CrossRef] [PubMed]

20. Armitage, S.A.O.; Fernández-Marín, H.; Wcislo, W.T.; Boomsma, J.J. An evaluation of the possible adaptive function of fungal brood covering by attine ants. Evolution 2012, 66, 1966-1975. [CrossRef]

21. Schoenian, I.; Spiteller, M.; Ghaste, M.; Wirth, R.; Herz, H.; Spiteller, D. Chemical basis of the synergism and antagonism in microbial communities in the nests of leaf-cutting ants. Proc. Natl. Acad. Sci. USA 2011, 108, 1955-1960. [CrossRef] [PubMed]

22. Taerum, S.J.; Cafaro, M.J.; Currie, C.R. Presence of multiparasite infections within individual colonies of leaf-cutter ants. Environ. Entomol. 2010, 39, 105-113. [CrossRef] [PubMed]

23. Gerardo, N.M.; Mueller, U.G.; Currie, C.R. Complex host-pathogen coevolution in the Apterostigma fungus-growing ant-microbe symbiosis. BMC Evol. Biol. 2006, 6, 88. [CrossRef]

24. Christopher, Y.; Wcislo, W.T.; Martínez-Luis, S.; Hughes, W.O.H.; Gerardo, N.M.; Fernández-Marín, H. Disease management in two sympatric Apterostigma fungus-growing ants for controlling the parasitic fungus Escovopsis. Ecol. Evol. 2021, 11, 6041-6052. [CrossRef] [PubMed]

25. Viney, M.E.; Graham, A.L. Patterns and processes in parasite co-infection. Adv. Parasitol. 2013, 82, 321-369.

26. Hochberg, M.E.; Holt, R.D. The coexistence of competing parasites. i. the role of cross-species infection. Am. Nat. 1990, 136, 517-541. [CrossRef]

27. Mabbott, N.A. The Influence of parasite infections on host immunity to co-infection with other pathogens. Front. Immunol. 2018, 9, 2579. [CrossRef]

28. Nowak, M.A.; May, R.M. Superinfection and the evolution of parasite virulence. Proc. Biol. Sci. 1994, 255, 81-89.

29. Mideo, N. Parasite adaptations to within-host competition. Trends. Parasitol. 2009, 25, 261-268. [CrossRef]

30. Alizon, S.; de Roode, J.C.; Michalakis, Y. Multiple infections and the evolution of virulence. Ecol. Lett. 2013, 16, 556-567. [CrossRef]

31. Leggett, H.C.; Benmayor, R.; Hodgson, D.J.; Buckling, A. Experimental evolution of adaptive phenotypic plasticity in a parasite. Curr. Biol. 2013, 23, 139-142. [CrossRef]

32. Bose, J.; Kloesener, M.H.; Schulte, R.D. Multiple-genotype infections and their complex effect on virulence. Zoology 2016, 119, 339-349. [CrossRef] [PubMed]

33. Vaumourin, E.; Vourch, G.; Gasqui, P.; Vayssier-Taussat, M. The importance of multiparasitism: Examining the consequences of co-infections for human and animal health. Parasit. Vectors. 2015, 8, 545. [CrossRef] [PubMed]

34. Shen, S.S.; Qu, X.Y.; Zhang, W.Z.; Li, J.; Lv, Z.Y. Infection against infection: Parasite antagonism against parasites, viruses and bacteria. Infect. Dis. Poverty. 2019, 8, 49. [CrossRef]

35. Susi, H.; Barrès, B.; Vale, P.F.; Laine, A.L. Co-infection alters population dynamics of infectious disease. Nat. Commun. 2015, 6, 5975. [CrossRef] [PubMed]

36. Gao, D.; Porco, T.C.; Ruan, S. Coinfection dynamics of two diseases in a single host population. J. Math. Anal. Appl. 2016, 442, 171-188. [CrossRef]

37. Cordero, O.X.; Datta, M.S. Microbial interactions and community assembly at microscales. Curr. Opin. Microbiol. 2016, 31, 227-234. [CrossRef]

38. Gorter, F.A.; Manhart, M.; Ackermann, M. Understanding the evolution of interspecies interactions in microbial communities. Philos. Trans. R. Soc. B Biol. Sci. 2020, 375, 20190256. [CrossRef]

39. Augustin, J.O.; Groenewald, J.Z.; Nascimento, R.J.; Mizubuti, E.S.G.; Barreto, R.W.; Elliot, S.L.; Evans, H.C. Yet more "weeds" in the garden: Fungal novelties from nests of leaf-cutting ants. PLoS ONE 2013, 8, e82265. [CrossRef]

40. White, T.J.; Bruns, T.D.; Lee, S.B.; Taylor, J.W. Amplification and direct sequencing of fungal ribosomal rna genes for phylogenetics. In PCR Protocols: A Guide to Methods and Applications; Innis, M.A., Gelfand, D.H., Sninsky, J.J., White, T.J., Eds.; Academic Press: Cambridge, MA, USA, 1990; pp. 315-322.

41. Meirelles, L.A.; Montoya, Q.V.; Solomon, S.E.; Rodrigues, A. New light on the systematics of fungi associated with attine ant gardens and the description of Escovopsis kreiselii sp. nov. PLoS ONE 2015, 10, e0112067. [CrossRef]

42. Masiulionis, V.E.; Cabello, M.N.; Seifert, K.A.; Rodrigues, A.; Pagnocca, F.C. Escovopsis trichodermoides sp. nov., isolated from a nest of the lower attine ant Mycocepurus goeldii. Antonie Leeuwenhoek Int. J. Gen. Mol. Microbiol. 2015, 107, 731-740. [CrossRef]

43. Montoya, Q.V.; Martiarena, M.J.S.; Polezel, D.A.; Kakazu, S.; Rodrigues, A. More pieces to a huge puzzle: Two new Escovopsis species from fungus gardens of attine ants. MycoKeys 2019, 46, 97-118. [CrossRef]

44. Katoh, K.; Standley, D.M. MAFFT Multiple sequence alignment software version 7: Improvements in performance and usability. Mol. Biol. Evol. 2013, 30, 772-780. [CrossRef] [PubMed]

45. Darriba, D.; Taboada, G.L.; Doallo, R.; Posada, D. jModelTest 2: More models, new heuristics and parallel computing. Nat. Methods. 2012, 9, 772. [CrossRef]

46. Stamatakis, A. RAxML version 8: A tool for phylogenetic analysis and post-analysis of large phylogenies. Bioinformatics 2014, 30, 1312-1313. [CrossRef] [PubMed]

47. Ronquist, F.; Teslenko, M.; van der Mark, P.; Ayres, D.L.; Darling, A.; Höhna, S.; Larget, B.; Liu, L.; Suchard, M.A.; Huelsenbeck, J.P. MrBayes 3.2: Efficient bayesian phylogenetic inference and model choice across a large model space. Syst. Biol. 2012, 61, 539-542. [CrossRef] [PubMed] 
48. Schultz, T.R.; Brady, S.G. Major evolutionary transitions in ant agriculture. Proc. Natl. Acad. Sci. USA 2008, 105, 5435-5440. [CrossRef] [PubMed]

49. Solomon, S.; Rabeling, C.; Sosa-Calvo, J.; Lopes, C.T.; Rodrigues, A.; Vasconcelo, H.; Bacci, M., Jr.; Mueller, U.G.; Schultz, T.R. The molecular phylogenetics of Trachymyrmex forel ants and their fungal cultivars provide insights into the origin and coevolutionary history of 'higher-attine' ant agriculture. Syst. Entomol. 2019, 44, 939-956. [CrossRef]

50. Schneider, C.A.; Rasband, W.S.; Eliceiri, K.W. NIH Image to ImageJ: 25 years of image analysis. Nat. Methods 2012, 9, 671-675. [CrossRef] [PubMed]

51. Mohammad, N.; Alam, M.Z.; Kabashi, N.A.; Adebayo, O.S. Development of compatible fungal mixed culture for composting process of oil palm industrial waste. Afr. J. Biotechnol. 2011, 10, 18657-18665. [CrossRef]

52. Morón-Ríos, A.; Gómez-Cornelio, S.; Ortega-Morales, B.O.; De la Rosa-García, S.; Partida-Martínez, L.P.; Quintana, P.; AlayónGamboa, J.A.; Cappello-García, S.; González-Gómez, S. Interactions between abundant fungal species influence the fungal community assemblage on limestone. PLoS ONE 2017, 12, e0188443. [CrossRef]

53. Garland, T., Jr.; Dickerman, A.W.; Janis, C.M.; Jones, J.A. Phylogenetic analysis of covariance by computer simulation. Syst. Biol. 1993, 42, 265-292. [CrossRef]

54. R Development Core Team. Spatial Analysis of Soybean Plant Height and Plant Canopy Temperature Measured with On-the-Go Tractor Mounted Sensors. In R: A Language and Environment for Statistical Computing; R Foundation for Statistical Computing: Vienna, Austria, 2019.

55. Boya, C.A.; Fernández-Marín, H.; Mejía, L.C.; Spadafora, C.; Dorrestein, P.C.; Gutiérrez, M. Imaging mass spectrometry and MS/MS molecular networking reveals chemical interactions among cuticular bacteria and pathogenic fungi associated with fungus-growing ants. Sci. Rep. 2017, 7, 5604. [CrossRef]

56. Bizarria, R.; Nagamoto, N.S.; Rodrigues, A. Lack of fungal cultivar fidelity and low virulence of Escovopsis trichodermoides. Fungal Ecol. 2020, 45, 100944. [CrossRef]

57. Marfetán, J.A.; Romero, A.I.; Cafaro, M.J.; Folgarait, P.J. Five new Escovopsis species from Argentina. Mycotaxon 2019, 133, 569-589. [CrossRef]

58. Kellner, K.; Kardish, M.R.; Seal, J.N.; Linksvayer, T.A.; Mueller, U.G. Symbiont-mediated host-parasite dynamics in a fungusgardening ant. Microb. Ecol. 2018, 76, 530-543. [CrossRef]

59. Paoletti, M. Vegetative incompatibility in fungi: From recognition to cell death, whatever does the trick. Fungal Biol. Rev. 2016, 30, 152-162. [CrossRef]

60. Malik, M.; Vilgalys, R. Somatic Incompatibility in Fungi. In Structure and Dynamics of Fungal Populations; Worrall, J.J., Ed.; Population and Community Biology Series; Springer: Dordrecht, The Netherlands, 1999; p. 25.

61. Dhodary, B.; Schilg, M.; Wirth, R.; Spiteller, D. Secondary metabolites from Escovopsis weberi and their role in attacking the garden fungus of leaf-cutting ants. Chem. Eur. J. 2018, 24, 4445-4452. [CrossRef]

62. Heine, D.; Holmes, N.A.; Worsley, S.F.; Santos, A.C.A.; Innocent, T.M.; Scherlach, K.; Patrick, E.H.; Yu, D.W.; Murrell, J.C.; Vieria, P.C.; et al. Chemical warfare between leafcutter ant symbionts and a co-evolved pathogen. Nat. Commun. 2018, 9, 2208. [CrossRef]

63. Weber, N.A. Gardening Ants, the Attines. In Memoirs of the American Philosophical Society; American Philosophical Society: Philadelphia, PA, USA, 1972; p. 146.

64. Caten, C.E. Vegetative incompatibility and cytoplasmic infection in fungi. J. Gen. Microbiol. 1972, 72, 221-229. [CrossRef] [PubMed]

65. Van Diepeningen, A.D.; Debets, A.J.M.; Hoekstra, R.F. Heterokaryon incompatibility blocks virus transfer among natural isolates of black Aspergilli. Curr. Genet. 1997, 32, 209-217. [CrossRef] [PubMed]

66. Gerardo, N.M.; Caldera, E.J. Labile associations between fungus-growing ant cultivars and their garden pathogens. ISME J. 2007, 1,373-384. [CrossRef]

67. Brglez, A.; Piškur, B.; Ogris, N. In vitro interactions between Eutypella parasitica and some frequently isolated fungi from the wood of the dead branches of young sycamore maple (Acer pseudoplatanus). Forests 2020, 11, 1072. [CrossRef]

68. Custodio, B.C.; Rodrigues, A. Escovopsis kreiselii specialization to its native hosts in the fungiculture of the lower attine ant Mycetophylax morschi. Antonie Leeuwenhoek Int. J. Mol. Microbiol. 2019, 112, 305-317. [CrossRef] [PubMed]

69. Gerardo, N.M.; Jacobs, S.R.; Currie, C.R.; Mueller, U.G. Ancient host-pathogen associations maintained by specificity of chemotaxis and antibiosis. PLoS Biology 2006, 4, e235. [CrossRef] [PubMed]

70. Poulsen, M.; Cafaro, M.J.; Erhardt, D.P.; Little, A.E.F.; Gerardo, N.M.; Tebbets, B.; Klein, B.S.; Currie, C.R. Variation in Pseudonocardia antibiotic defence helps govern parasite-induced morbidity in Acromyrmex leaf-cutting ants. Environ. Microbiol. Rep. 2010, 2, 534-540. [CrossRef]

71. Cafaro, M.J.; Poulsen, M.; Little, A.E.F.; Price, S.L.; Gerardo, N.M.; Wong, B.; Stuart, A.E.; Larget, B.; Abbot, P.; Currie, C.R. Specificity in the symbiotic association between fungus-growing ants and protective Pseudonocardia bacteria. Proc. R. Soc. B Biol. Sci. 2011, 278, 1814-1822. [CrossRef] [PubMed] 